\title{
Acompanhante de Adulto na Unidade de Terapia Intensiva: uma visão do Paciente*
}

\author{
Patients' Views of an Adult Companion in the Intensive Care Unit \\ Acompañante del Adulto internado en una Unidad de Cuidados Intensivos: una visión del Paciente
}

\section{Márcia Rodrigues Maciel'1, Mariana Fernandes de Souza ${ }^{2}$}

\begin{abstract}
RESUMO
Objetivo: identificar se o cliente adulto gostaria de ter um acompanhante enquanto internado na Unidade de Terapia Intensiva (UTI) e relacionar a sua opinião com as variáveis sexo, idade, estado civil, escolaridade, gravidade da doença, tempo de internação e número de vezes que permaneceu em uma UTI. Métodos: o instrumento utilizado foi um formulário aplicado por meio de entrevista com pacientes que ficaram internados na UTI por um período mínimo de 24 horas. A amostra constituiu-se de 138 pacientes. Resultado: dos participantes do estudo $44.9 \%$ eram do sexo feminino e $55.1 \%$ do sexo masculino sendo que $58.7 \%$ concordaram e $41.3 \%$ não concordaram com a permanência de um acompanhante. A correlação entre as variáveis mostrou significância entre desejar a presença de acompanhante e o número de vezes de internação em UTI $(p=0.03$ ). Houve também significância entre querer acompanhante e ser do sexo feminino $(p=$ 0.051). Nas demais variáveis não tiveram significância. Conclusão: este estudo mostrou a necessidade de perguntar ao doente se deseja um acompanhante e em que momento da internação.
\end{abstract}

Descritores: Acompanhantes de pacientes; Unidades de terapia intensiva; Equipe de enfermagem

\begin{abstract}
Objective: to identify whether or not adult clients would benefit from a companion when admitted to an Intensive Care Unit (ICU). The study variables included gender, age, marital status, educational level, disease acuity, and the number of admission to the ICU. Methods: this was a descriptive study. Data were collected using semi-structured interviews. Participants included 138 adult clients admitted to an ICU for at least 24 hours. Results: the majority of the participants were male (55.1\%). Approximately 59\% of the participants reported a preference for the presence of a companion. There was a significant association between a preference for a companion and the number of ICU admission $(p=0.03)$. There was also a significant association between the female gender and the preference for a companion $(p=0.05)$. The remaining variables were non-significant. Conclusion: the study's findings suggest the need to ask adult clients if they desire a companion on admission to an ICU.
\end{abstract}

Keywords: Patient escort service; Intensive care unit; Nursing, team

\section{RESUMEN}

Objetivo: identificar si el cliente adulto desearía tener un acompañante durante su internamiento en la Unidad de Cuidados Intensivos (UCI) y relacionar su opinión con las variables sexo, edad, estado civil, escolaridad, gravedad de la enfermedad, tiempo de internamiento y número de veces que permaneció en una UCI. Métodos: el instrumento utilizado fue un formulario aplicado por medio de entrevista a los pacientes internados en la UCI por un período mínimo de 24 horas. La muestra estuvo constituida de 138 pacientes. Resultado: de los participantes del estudio el $44.9 \%$ fue del sexo femenino y el 55.1\% del masculino. El 58.7\% concordó y el $41.3 \%$ no concordó con la permanencia de un acompañante. La correlación entre las variables fue significativa entre desear la presencia del acompañante y el número de veces de internamiento en la UCI ( $\mathrm{p}=0.03)$. Los datos también fueron significativos entre el querer acompañante y ser del sexo femenino $(\mathrm{p}=0.051)$. Las demás variables no fueron significativas. Conclusión: con este estudio se demostró la necesidad de preguntar al enfermo si desea o no un acompañante y en qué momento del internamiento.

Descriptors: Acompañantes de pacientes; Unidades de terapia intensiva; Grupo de enfermería

\footnotetext{
* Trabalho extraído da dissertação de mestrado, apresentada à Universidade Federal de São Paulo - UNIFESP - São Paulo (SP), Brasil.

${ }^{1}$ Mestre em Enfermagem pela Universidade Federal de São Paulo - UNIFESP - São Paulo (SP), Brasil.

${ }^{2}$ Professora Titular do Departamento de Enfermagem da Universidade Federal de São Paulo - UNIFESP - São Paulo (SP), Brasil.
} 


\section{INTRODUÇÃO}

A característica do atendimento na Unidade de Terapia Intensiva (UTI), envolvendo complexidade tecnológica, gravidade da doença, e necessidade de ação imediata leva os profissionais que atuam nesta área a priorizar as atividades técnicas. O cliente internado é tratado como se fosse mais um leito ou um caso de doenaça. As regras institucionais são rígidas em relação às visitas e acompanhantes. Determina-se o horário e número de pessoas que podem visitar, favorecendo a instituição e não o doente. No momento da internação exige-se a entrega de todos os pertences, descaracterizando-o do seu mundo real. É comum na instituição hospitalar os colaboradores tratarem o cliente como se fosse uma criança, elaborando as frases no diminutivo. A autoridade também é utilizada, não respeitando a vontade do mesmo. É mantido sem roupa para facilitar uma eventual emergência, os cuidados são prestados muitas vezes em locais abertos por, problemas na planta física ou não cumprimento da ética pelos profissionais. O Código de Ética de Enfermagem referenda, como dever do profissional, respeitar o natural pudor, a privacidade e a intimidade do cliente $^{(1)}$.

Além de todo o estresse a que são submetidos, os doentes, no ambiente da UTI, também são privados da companhia de pessoas da familia e dos amigos. Quando conceituamos a saúde como um equilíbrio biopsicosso-cioespiritual, deveríamos inserir, no contexto hospitalar, a presença da família que traz segurança afetiva ao doente. A pessoa internada faz parte do sistema familiar e a hospitalização em UTI é um evento de crise, tanto para ela quanto para a familia e a enfermeira deve avaliar as necessidades físicas e psicológicas de ambas e incorporá-las nas necessidades levantadas ${ }^{(2)}$. A informação oferecida ao familiar é muito importante, principalmente para conhecer o que é uma UTI, o que se faz para os clientes internados e como é o trabalho dos funcionários dessa unidade. O familiar precisa estar seguro de que a pessoa internada receberá toda a assistência de que necessita. Por outro lado, os funcionários parecem não saber como poderão transmitir essa segurança, tanto no que se refere ao tipo de informação que poderá ser dada, como na interpretação dos cuidados prestados. A ansiedade e a desconfiança inicial do familiar e do doente são resultados da própria situação de internação sendo amenizadas por meio das informações dadas ${ }^{(3)}$. A enfermeira como elemento integrante da equipe, tem a responsabilidade de informar e orientar o familiar, com a finalidade de amenizar os sentimentos de angústia( ${ }^{(4)}$. A informação dada pela enfermeira, deveria estar mais integrada nesse processo, uma vez que mantém um estreito e contínuo contato com o doente e seus familiares e a comunicação, para ser eficaz, deve conter uma mensagem que possa ser entendida facilmente. Muitas das falhas no processo de informação são causadas por simples erros de compreensão. A participação da enfermeira pode proporcionar ajuda aos familiares, especialmente quando não compreendem a informação dada pelo médico ${ }^{(5)}$.

É freqüente a proibição de visitas em UTI e quando são permitidas, as rotinas e condições impostas têm, como prioridade, o atendimento as necessidades técnicas da unidade ${ }^{(6)}$. Há muita resistência das instituições e dos profissionais quanto à liberação de visitas em Terapia Intensiva de Adulto, enquanto que UTI pediátrica a liberação é mais freqüente. O acompanhante é fonte de conforto e segurança, um elo com a equipe, um fator de melhoria da qualidade da assistência prestada. É também considerada uma ajuda em potencial na assistência, além de uma oportunidade de educação em saúde ao familiar. A permanência de um acompanhante contribui para a humanização, pois o avanço tecnológico transforma o ambiente e as pessoas que nele trabalham. Ele passa a ser um elo entre a equipe, a família e a pessoa doente. Em recente estudo, o papel do consumidor começa a ter destaque. O profissional da área de saúde passa a ser julgado e o cliente toma decisões sobre os cuidados médicos. O foco volta-se para a qualidade do atendimento com menor custo e satisfação de quem é atendido ${ }^{(7)}$.

A transparência no cuidar é essencial, o consumidor busca seus direitos baseados em lei. A permanência de um acompanhante durante a internação em UTI não deve ameaçar a instituição e os profissionais da saúde, desde que estes pratiquem o atendimento com qualidade. A presença do acompanhante é uma das formas de garantir a qualidade no atendimento.

Existem poucos estudos sobre a percepção do próprio doente quanto à permanência de um acompanhante enquanto internado em uma UTI. A experiência profissional levou a observar diversas respostas do cliente em relação à visita na UTI. Uns não queriam receber visita, pois na sua percepção, encontravam-se em uma condição humana muito precária e não queriam ser vistos dessa forma. Outros pediam para que alguém ficasse fazendo companhia e escolhiam sempre a pessoa mais próxima do núcleo familiar.

É necessário considerar que, quando se abre o hospital para o público, é preciso de mais investimento em recursos humanos e materiais. Para os doentes, a avaliação e exigência dos seus direitos ficarão muito mais fáceis, se realmente souberem o que acontece dentro de uma UTI.

A importância do tema e, ao mesmo tempo, a diversidade de considerações levou à realização deste estudo que buscou ouvir os doentes sobre a presença de um acompanhante enquanto internados em UTI, esperando trazer subsídios para decisões relativas a essa questão.

\section{OBJETIVOS}

* identificar se o cliente adulto internado na UTI gostaria 
de ficar com um acompanhante durante a internação.

* correlacionar a opinião do cliente sobre a permanência de acompanhante na UTI com as variáveis: sexo, idade, escolaridade, estado conjugal, gravidade da doença, dias de internação e número de vezes que ficou internado na UTI.

\section{MÉTODOS}

Estudo quantitativo de natureza descritiva e de correlação. Após aprovação do Comitê de Ética e Pesquisa do Hospital São Paulo-UNIFESP e da Instituição campo da pesquisa, iniciou-se a coleta de dados, a qual foi feita em um hospital geral particular, de médio porte, com dez leitos de Terapia Intensiva. A população foi constituída pelos clientes adultos que ficaram internados na UTI do hospital campo de estudo, no período de outubro de 1999 a setembro de 2000. Compuseram a amostra os pacientes que preencheram os seguintes critérios:

* pertencer à faixa etária de vinte a setenta e cinco anos.

* não ter permanecido em estado de coma ou de confusão mental durante o tempo de internação na UTI.

* Ter ficado internado pelo tempo mínimo de vinte e quatro horas na UTI.

Variáveis selecionadas: sexo, idade, escolaridade, estado conjugal, avaliação da gravidade da doença, dias de internação e internações anteriores em UTI.

Sexo: diante das diferenças entre características biológicas e psicológicas masculinas e femininas, procurou-se verificar se o sexo influenciaria o querer ou não a presença de acompanhante.

Idade: interfere na preferência do cliente quanto ao tempo que a visita deve permanecer na UTI ${ }^{(8)}$. Em estudo desenvolvido de correlação entre pacientes internados em UTI e Unidade coronariana com a preferência por visita, a idade teve forte relação com a preferência por visita. Os pacientes mais velhos preferiram visitas mais longas, enquanto os mais jovens preferiram visitas mais $\operatorname{curtas}^{(9)}$. O limite de idade para fazer parte da amostra foi considerado por ser esta faixa etária a mais comum na UTI campo de estudo.

Escolaridade: pode exercer influência nas experiências de vida das pessoas e foi categorizada da seguinte forma:

* sem instrução - os que referiram ser analfabetos.

*ensino fundamental incompleto - os que não completaram este nível de ensino.

* ensino médio incompleto - os que completaram o ensino fundamental, mas não terminaram o ensino médio.

* ensino superior incompleto - os que terminaram o ensino médio, mas não concluíram o ensino superior.
* ensino superior completo - completaram o ensino superior.

Estado conjugal: a vida com um companheiro poderia levar a sentir necessidade dele durante a internação, enquanto os clientes solteiros não teriam esta referência durante a hospitalização. Foi categorizada em:

* casado - a pessoa que vive com um companheiro

* solteiro - a que não têm um companheiro

* viúvo - a que o companheiro já faleceu

* outros - divorciados e separados

Avaliação da gravidade da doença: foi utilizado o índice prognóstico APACHEII (Acute Physiology and Chronics Health Evaluation) o qual determina os principais fatores de sobrevida de um cliente crítico, como desvio fisiológico agudo, reserva fisiológica do cliente e o diagnóstico da doença de base. A coleta de dados é feita nas primeiras vinte e quatro horas na UTI. O APACHE II consiste de um escore numérico (variando de 0 a 71). Um aumento do escore do APACHE II reflete um aumento da gravidade da doença e um maior risco de morrer no hospital. Buscamos saber se a gravidade influi na necessidade de ter um acompanhante enquanto internado na UTI ${ }^{(10)}$.

Dias de internação: foi considerado o tempo que o cliente ficou internado na UTI, até ser transferido para a unidade de internação.

Internações anteriores em UTI: avaliado se o cliente permaneceu ou não internado anteriormente em UTI e se, de fato, tem relação com a necessidade de ter acompanhante na internação atual.

A coleta de dados foi feita por meio de entrevista com um roteiro (Anexo 1). Este foi aplicado individualmente às pessoas amostradas pela pesquisadora, após 24 horas de o doente ter saído da UTI e ser encaminhado à enfermaria.

Para análise dos dados foram utilizados os seguintes testes: teste do quiquadrado ${ }^{(11)}$, prova exata de Fisher e teste de Mann Whitney ${ }^{12}$.

\section{RESULTADOS}

a) Resultados descritivos das variáveis de estudo

A amostra constitui-se de 138 pacientes, sendo $44.9 \%$ do sexo masculino e $55.1 \%$ do sexo feminino. Em relação à idade, $15.9 \%$ encontravam-se na faixa etária menor que 40 anos; $19.5 \%$ na faixa de 40 a 49 anos; $47.3 \%$ entre 50 e 69 e $17.3 \%$ com idade igual ou acima de 70 anos. A amostra se caracterizou por maior porcentagem de clientes casados, $72.5 \%$. entre os clientes da amostra o grau de instrução predominante foi o ensino médio incompleto $(40.7 \%)$, seguido de ensino fundamental incompleto $(23.9 \%)$. As menores porcentagens ficaram com clientes sem instrução (9.4\%) e ensino superior completo $(7.2 \%)$. Houve predomínio 
de pacientes com um resultado (APACHE II) que indica bom prognóstico. Dos clientes analisados, $65.2 \%$ tiveram resultado do APACHE II entre 7 e 15. Quando analisado o tempo de permanência, a maior porcentagem (85.5\%) foi de clientes com tempo de permanência menor que quatro dias. Quando analisamos número de vezes que o cliente ficou internado anteriormente na UTI, percebemos predomínio dos que ficaram internados somente uma vez $(60.5 \%)$ seguidos de duas internações $(28.9 \%)$ e três internações $(10.5 \%)$. A opinião manifestada pelos clientes não indicou, porcentualmente, grande diferença em querer ou não a presença de acompanhante, pois $58.7 \%$ responderam afirmativamente que gostariam da permanência de um acompanhante e $41.3 \%$ não gostariam da permanência de um acompanhante.

\section{b) Resultados da correlação entre as variáveis de estudo}

A variável idade, quando feita a correlação com a opinião do cliente em ficar ou não com acompanhante, não demonstrou resultado significante $(\mathrm{p}=0,464)$. Neste estudo, a maior concentração de clientes entrevistados se encontravam na faixa etária acima de 50 anos, confirmando a característica de usuário da UTI ser uma população mais idosa. A média de idade dos clientes foi de 53 anos. Na correlação com a idade, utilizamos o teste de Mann Whitney devido ser uma variável ordinal contínua.

A variável estado conjugal não mostrou correlação entre desejar ou não de permanecer com acompanhante, isto é, não influenciou a opinião do cliente $(p=0,658)$. Também não houve correlação com a variável gravidade da doença enquanto internado na UTI. (Teste de Mann Whitney, $\mathrm{p}=0$,774). Alguns clientes relataram preferir ficar com acompanhante, após passar o período crítico da doença.

A análise estatística, de acordo com o teste Mann Whitney, mostrou que o $p$ não foi significante, quando se relacionou dias de internação na UTI e a opinião de ficar ou não com acompanhante $(\mathrm{p}=0,743)$.

Neste estudo, foi observada correlação positiva significante entre internações anteriores em UTI e querer permanecer com acompanhante, $(p=0,03)$ (Fig. 1). Dos pacientes internados uma única vez, $52 \%$ gostariam de ficar com acompanhante e dos internados duas vezes ou mais, $73 \%$ manifestaram este desejo.

O sexo foi uma das variáveis que teve correlação positiva com o querer permanecer com acompanhante. $O$ teste utilizado encontrou um resultado significante $(p$ $=0.051$ ) (Fig. 2). É possível que, a mulher devido a sua característica em sempre estar disponível para ajudar parentes e pessoas próximas, tenha um maior conhecimento da rotina do cuidador e, quando se encontra na posição de ser cuidada, busca naturalmente a companhia de um familiar.

Figura 1 - Clientes internados na Unidade de Terapia Intensiva de um hospital particular de São Paulo no período de outubro de 1999 a setembro de 2000, segundo preferência por ficar ou não com acompanhante e o número de internações em UTI. São Paulo, 2005.

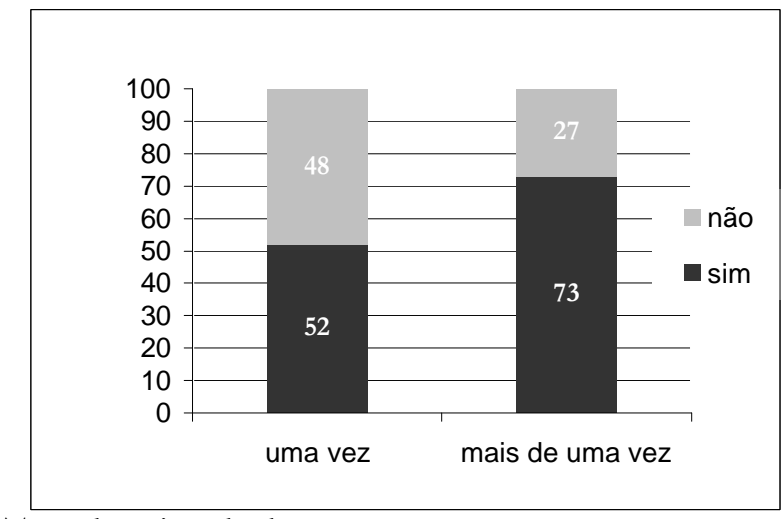

Teste do quiquadrado $p=0,03$

Figura 2 - Clientes segundo o sexo e a opinião de ter ou não acompanhante em UTI de um Hospital particular de São Paulode outubro de 1999 a setembro de 2000. São Paulo, 2005.

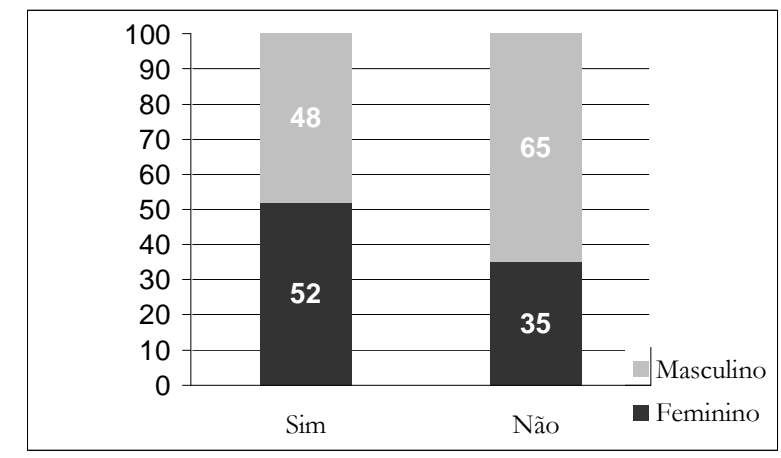

Teste do quiquadrado

$\mathrm{p}=0,051$

\section{DISCUSSÃO}

Foram encontrados artigos que relatam estudos das visitas pela perspectiva dos familiares ${ }^{(8)}$ e funcionários ${ }^{(13)}$, porém poucos são os que avaliam as preferências dos clientes. As razões alegadas para restringir as visitas aos clientes são possibilitar seu descanso e recuperação. Foi feito um estudo em que as visitas foram restritas para um período de quinze minutos quatro vezes ao dia, com o propósito de prover esse descanso. O resultado mostrou que os trabalhadores da área de saúde foram os maiores interruptores do descanso, chegando-se à conclusão de que restringir as visitas não facilita o descanso do cliente ${ }^{14}$. A prática de limitar visitas em UTI não tem base científica, pois se fundamenta na crença 
de que a presença de parentes ao lado da cama seria mais estressante para os clientes graves do que a presença dos trabalhadores da área. Sabemos que qualquer aproximação do leito é vista pelo cliente como indícios de procedimento invasivo e doloroso. A dor gera medo com resposta do sistema nervoso simpático, levando à ansiedade e conseqüente estresse. Desde o surgimento das primeiras salas de Terapia Intensiva, houve resistência em autorizar a presença de acompanhantes, com base em argumentos sobre possível aumento de infecções. Um estudo desenvolvido em 1990 concluiu que houve aumento da carga bacteriana durante o ano em que foi instituída a presença de acompanhante na Terapia Intensiva, mas as bactérias isoladas eram de elevada resistência aos antibióticos usuais e em nenhum momento poderiam ter sido introduzidas pelos acompanhantes ${ }^{(15)}$.

Este estudo mostrou que existem clientes que preferem não ter acompanhante enquanto internados na UTI. As razões dadas para essa opção foram relacionadas à preocupação com os familiares e por se sentirem seguros e bem atendidos. Entre as preocupações com a família, destacam-se as seguintes: a família não pode ajudar, irá sofrer, a família fica preocupada, o ambiente é muito estressante, a pessoa leiga sofre dentro da UTI, não tem ninguém disponível na família para ficar como acompanhante, prefere poupar os membros da familia.

O local onde foram coletados os dados pode ter influenciado o resultado de querer ou não acompanhante, enquanto internado em UTI, por ser um hospital com maior abertura a visitas, e mesmo ao acompanhante.

As justificativas apresentadas pelos clientes que opinaram a favor da presença de acompanhante mostram divergências quanto ao momento em que desejariam a companhia. Alguns afirmaram que gostariam da presença de um acompanhante somente após ter sido desentubados, ou após recobrar a consciência, ou somente após melhorar. Outros afirmaram preferir acompanhante nos momentos em que estivessem mais graves. Essas opiniões indicam que se deve perguntar aos clientes se preferem e desejam ter acompanhante junto a si.

\section{CONCLUSÕES}

Os resultados deste estudo permitem as seguintes conclusões:

$\mathrm{Na}$ amostra de 138 clientes, 58.7\% manifestaram a preferência por afirmativa sobre ter acompanhante, enquanto internados em UTI, e $41.3 \%$ preferiram não ter a presença de acompanhante.

A correlação da opinião sobre a presença ou não de acompanhante enquanto internado em UTI foi significativa para as seguintes variáveis:
* sexo $(\mathrm{p}=0,051)$ o sexo feminino manifestou maior preferência em ficar com acompanhante;

* internações anteriores em UTI ( $\mathrm{p}=0,03)$; quanto maior o número de vezes que o cliente se internou em UTI, maior a preferência por ficar com acompanhante.

A correlação com as demais variáveis não foi significativa.

\section{REFERÊNCIAS}

1. Conselho Regional de Enfermagem de São Paulo. Documentos básicos de enfermagem: enfermeiros técnicos, auxiliares/ COREN-SP. São Paulo: COREN-SP; 2001.

2. Alpen MA, Halm MA. Family needs: an annotated bibliography. Crit Care Nurse. 1992; 12(2): 41-50.

3. Almeida VAL, Narciso RB, Uechi K. Visitas em UTI: uma abordagem frente os sentimentos dos familiares e da equipe de enfermagem. In: Primeiro Ciclo de Debates sobre Assistência de Enfermagem. Anais. 1988; p. 276-92.

4. Lautert L, Echer IC, Unicovsky MAR. O acompanhante do paciente adulto hospitalizado. Rev Gaúch Enferm. 1998; 19(2):118-31.

5. Bernat Adell MD, Tejedor Lopez R, Sanchis Munoz J. Como valoran y comprenden los familiares la information proporcionada una unidad de cuidados intensivos? Enferm Intensiva. 2000; 11(1):3-9.

6. Souza RMC. Visitas em UTI: subsídios para reflexão. Rev Paul Hosp. 1988; 36(1/3):24-9.

7. Johnson D, Wilson M, Cavanaugh B, Bryden C, Gudmundson D, Moodley O. Measuring the ability to meet family needs in an intensive care unit. Crit Care Med.1998; 26(2): 266-71.

8. Simpson T. Critical care patients' perceptions of visits. Heart Lung. 1991; 20(6):681-8.

9. Simpson T. Visit preferences of middle-aged vs older critically ill patients. Am J Crit Care. 1993; 2(4):339-45.

10. Junior DFM, Guastelli LR, Almeida FP. Índices de gravidade. In: Knobel E. Terapia Intensiva: Enfermagem. São Paulo: Atheneu; 2006. cap. 10. p.93-114.

11. Levin J. Estatística aplicada a ciências humanas. $2^{\circ}$ ed. São Paulo: Harbra; 1987. 392p.

12. Siegel S. Estatística não paramétrica. São Paulo: Mcgraw Hill; 1979. 349p.

13. Lacerda AC, Carvalho ACS, Rocha RM, Acompanhantes no centro de terapia intensiva: percepção da equipe de enfermagem. Rev Enfermagem UERJ. 2004;12(1):18-23.

14. Heater BS. Nursing responsibilities in changing visiting restrictions in the intensive care unit. Heart Lung. 1985; 14(2): 181-6.

15. González-Rodriguez I, Camacho Assef V, Cadre Raton AM. Atención psicológica del acompanãnte em unidades de cuidados intensivos. Rev. Hosp. Psiquiátr La Habana. 1990; 31 (1): 107-12. 


\section{ANEXO 1}

Roteiro para Entrevista

1. IDENTIFICAÇÃO

1.1. $R G$ bospitalar:

1.2. Idade:

1.3. Sexo: $M() F()$

1.4. Estado conjugal: Casado(） Solteiro( ) Viúvo () Outros:

1.5. Escolaridade: Sem instrução ()

Ensino Fundamental Incompleto （）

Ensino Médio Incompleto （）

Ensino Superior ( ) incompleto

( ) completo

2. DADOS DO PACIENTE COLHIDOS NO PRONTUÁRIO

2.1. Dias de internação na UTI:

2.2. Gravidade da doença: Apache II

3. QUESTÕES

3.1. Já ficou internado na UTI anteriormente? não（） sim（） quantas vezes?

3.2. Enquanto esteve internado na UTI o Sr/Sra recebeu visita? não（） sim（）

3.3. Gostaria que algum amigo ou familiar ficasse junto enquanto esteve internado na UTI? não( ) $\operatorname{sim}($ )

Se a resposta for afirmativa. Em que momento?-

Quem?-

3.4. Perguntar porquê e colocar na observação.

OBSERVAÇÕES: 